\section{COVID-19: A Matter Close to the Heart}

Gláucia Maria Moraes de Oliveira ${ }^{\circledR}$ and Fausto J. Pinto ${ }^{2}$

Universidade Federal do Rio de Janeiro (UFRJ), ${ }^{\prime}$ Rio de Janeiro, RJ - Brazil CCUL, Faculdade de Medicina, Universidade de Lisboa, ${ }^{2}$ Lisboa - Portugal

The world is facing a new challenge, the novel coronavirus disease 2019 (COVID-19), caused by a betacoronavirus named severe acute respiratory syndrome coronavirus 2 (SARS-CoV-2), phylogenetically identical to the SARS-CoV (severe acute respiratory syndrome coronavirus) and the MERS-CoV (Middle East respiratory syndrome coronavirus) responsible for innumerable deaths in China in 2003 and in the Middle East in 2012, respectively.

On March 11, 2020, the COVID-19 outbreak was characterized as a pandemic by the World Health Organization (WHO). ${ }^{1}$ Twenty-three days after that announcement, the cases reported reached 1,056,777 in 182 countries, with 55,781 deaths, most of which occurring in Italy, Spain, France, China and Iran. So far, Brazil has registered 8,195 cases and 335 deaths, while Portugal, 9,886 cases and 246 deaths, figures that have increased steeply since the beginning of the pandemic. ${ }^{2}$

In the face of this exponential increase, mainly in São Paulo and Rio de Janeiro states, multiple safeguarding measures to prevent further spread of the virus, such as school dismissal, event cancellations, reduced bank hours, closure of commerce, except for essential sectors, recommendation for home confinement, and cancellation of public transportation between municipalities and states, have been taken in Brazil, as well as in Portugal and other countries. In the absence of a vaccine and specific therapy, that is actually the only way to restrain viral spread and to prevent the health system overload, which might lead to its collapse, as seen, for example, in Italy and Spain. Person-to-person spread via respiratory

\section{Keywords}

Coronavirus-19 (COVID-19); Severe Acute Respiratory Syndrome; Dyspnea; Risk Factors; Fever; Mortality; Pandemics; Cardiovascular Diseases/complications. droplets disseminated during sneezing, coughing and talking, as well as transmission through contact with contaminated surfaces justifies those measures. ${ }^{3}$ The PCR assay for viral RNA detection on respiratory tract samples has been used for the laboratory diagnosis of COVID-19; moreover, wide-scale testing has been adopted to contain the pandemic in other countries. ${ }^{3}$ Other types of tests are being developed to assess the population acquired immunity. These tests identify individuals who have developed immunity to the virus, and who can therefore safely return to their usual activities. This will be essential in the second phase of the pandemic.

Analyses by the Imperial College with projections from the COVID-19 cases have estimated, if no action is taken, 7 billion infections and 40 million deaths worldwide in 2020. Furthermore, they have reported that mitigation strategies focused on protection could cut that burden in half, saving 20 million lives, but not without overloading healthcare services, a situation that might be even more severe in lower income settings. ${ }^{4}$ This scenario should be avoided at any cost by implementing strict measures that limit the movement of people, as well as social distancing or even isolation. It is worth noting that underreporting, undertesting and delayed confirmatory test results might jeopardize the statistics of any country that does not adopt a strict policy for test performance, as recommended by the WHO.

A study conducted in China with 72,314 patients with COVID-19 (44,672 laboratory-confirmed cases, 16,186 suspected cases, and 10,567 clinically diagnosed cases) has reported mild clinical severity in $81.4 \%$ of the sample, severe clinical severity in $13.9 \%$, and critical clinical severity in $4.7 \%{ }^{3}$ The most common symptoms were fever, cough, dyspnea, myalgia, fatigue, and diarrhea., ${ }^{3,5}$ Other signals and symptoms have been reported, such as sore throat, chest pain, mental confusion, and lethargy.

Mailing Address: Gláucia Maria Moraes de Oliveira

Universidade Federal do Rio de Janeiro - R. Prof. Rodolpho P. Rocco, 255 - Prédio do HU 8º andar - sala 6, UFRJ. Postal Code: 21941-913, Cidade Universitária, RJ - Brazil. E-mail: glauciam@cardiol.br, glauciamoraesoliveira@gmail.com 
Almost $5 \%$ of the infections will have a severe course with acute respiratory distress syndrome, pulmonary bleeding, severe lymphopenia, kidney failure, circulatory shock, and failure of multiple organs. ${ }^{3,5}$ The case-fatality rates by age group in Italy $(1,625$ cases $)$ and China (1,023 cases) differed substantially, $7.2 \%$ and $2.3 \%$, respectively, which can be partially explained by the older age distribution in Italy, as well as the presence of more comorbidities among Italians. ${ }^{6}$

One fourth to half of the patients with COVID-19 have chronic conditions, especially cardiovascular (CVD) and cerebrovascular diseases, which increase the risk for a severe course of disease and death. A meta-analysis of six studies conducted in China, including 1,527 patients with COVID-19, has assessed the prevalence of CVD and reported the following proportions: hypertension, $17.1 \%$; heart and cerebrovascular diseases, $16.4 \%$; and diabetes, 9.7\%. ${ }^{7}$ Another study with 44,672 confirmed cases of COVID-19 in China has shown preexisting comorbidities, such as CVD (10.5\%), diabetes $(7.3 \%)$, and hypertension $(6 \%)$, which related to a case-fatality rate of $2.3 \% .^{3}$ Those studies have evidenced the importance of not only chronic diseases but also of age and host immune status to COVID-19-related mortality, characterizing a complex, multifactorial and bidirectional model that can comprise the drugs used to treat those pathologies. ${ }^{8,9}$

Acute and chronic cardiovascular complications have been observed and attributed to several mechanisms, such as relative ischemia, systemic inflammation and pathogen-mediated damage, with increased levels of biomarkers, such as troponin I, BNP, and d-dimer. ${ }^{9-11}$ Myocardial damage was observed in $7.2 \%$ of patients with SARS-CoV-2 pneumonia, shock in $8.7 \%$, and arrhythmia in $16.7 \%$, leading to intensive care admission. ${ }^{9}$ A meta-analysis with four studies, including 341 COVID-19 patients, has reported a significantly higher standardized mean difference in cardiac troponin I levels in patients with severe disease as compared to those with milder disease (25.6; 95\%CI: 6.8-44.5 ng/L). ${ }^{10}$ In a retrospective multicenter cohort study in China, elevated d-dimer levels at admission $(>1 \mu \mathrm{g} / \mathrm{mL}$ ) have been associated with in-hospital death even after adjustments (OR 18.4; 95\% CI: 2.6-128.6 $\mu \mathrm{g} / \mathrm{mL}){ }^{11}$

Venous thromboembolism in COVID-19 has been reported, probably due to vascular inflammation, hypercoagulable states and endothelial dysfunction. ${ }^{8}$ Fulminant myocarditis and heart failure have been associated with SARS-CoV-2 infection; moreover, preexisting coronary artery disease has been associated with a possible predisposition to that infection. ${ }^{12-14}$ In a case series with 150 patients with COVID-19, 7\% of the 68 deaths were attributed to myocarditis with circulatory failure. ${ }^{12}$ Other studies have described fulminant myocarditis with high viral load and the post-mortem finding of mononuclear inflammatory infiltrates in the heart tissue. ${ }^{13,14} \mathrm{New}$ and important knowledge was recently presented in a case report: the lack of any pulmonary manifestation in a patient with myopericarditis and significant left ventricular dysfunction, who tested positive for SARS-CoV-2 and was successfully treated with dobutamine, lopinavir/ ritonavir, steroids, chloroquine, and the usual medical therapy for heart failure.${ }^{15}$ In another study, heart failure has been observed in $23.0 \%$ of the COVID-19 patients, being associated with non-survivors ( $51.9 \%$ vs. $11.7 \%$ ); in addition, the contribution of previous ventricular dysfunction to that outcome remains inconclusive. ${ }^{11}$

Murine models and human post-mortem samples have shown that SARS-CoV can regulate the myocardial and pulmonary angiotensin-converting-enzyme 2 (ACE2), mediating myocardial inflammation, pulmonary edema and acute respiratory failure, and might explain the cardiovascular involvement of severely ill patients. ${ }^{16}$ However, data available are still insufficient to determine whether these observations readily translate to humans, and no study has evaluated the effects of renin-angiotensinaldosterone system inhibitors in patients with COVID-19.17

Some studies have suggested that ACE inhibitors (ACEI) and angiotensin-receptor blockers (ARB) can up-regulate ACE2, thus increasing susceptibility to the virus; other studies, however, have shown that ACEI / $\mathrm{ARB}$ can potentialize the pulmonary protective function of ACE2. ${ }^{18,19}$ The Brazilian Society of Cardiology, the European Society of Cardiology and the American College of Cardiology recommend the individualized assessment of the patient, suggesting that the abrupt withdrawal of therapeutic schemes currently being practiced should not be performed, as that might cause clinical instability and adverse health outcomes.

At the current time there is neither a vaccine against nor a specific treatment for COVID-19. Chloroquine blocks the viral infection by increasing the endosomal $\mathrm{pH}$ necessary for the virus/cell fusion and has shown an inhibitory effect on SARS-CoV-2 in vitro. Ribavirin, lopinavir/ritonavir and remdesivir are antiviral drugs being tested in prospective studies. It is worth noting that the lopinavir/ritonavir 
association alters heart conduction, with QT-interval prolongation and advanced atrioventricular block. In addition, those drugs interact with antiplatelet agents, anticoagulants, statins and beta-blockers .8,20

When approaching patients with COVID-19, cardiologists should be alert to new clinical manifestations, such as arrhythmias, left ventricular dysfunction and systemic embolism, which might be related to that condition, since there is much that is still unknow about it.

The COVID-19 pandemic came to change, in a previously unimaginable way, the dynamics and functioning of societies worldwide. The challenges are gigantic, mainly concerning the strain they represent to national health systems, which have never been submitted to such a radical stress test. However, this can also be an opportunity to reorganize and strengthen health systems, and, at the same time, to highlight the pivotal role of health professionals in our society. Policymakers should pursue the most effective way to guarantee the sustainability of health systems, while ensuring that healthcare professionals receive just reward and due recognition for their effort and dedication, often ignored in times of Peace.

The world has responded to this scenario of global crisis with unprecedented widespread solidarity. In light of the enormous challenges that lie ahead, we must ensure that this matter remains close to heart.

\section{References}

1. World Health Organization. WHO. Director-General's opening remarks at the media briefing on COVID-19 - 11 March 2020. [Internet]. [Cited in $2020 \mathrm{March}$ 21] [Epub ahead print]. Available from: https://www.who.int/dg/speeches/detail/ whodirector-general-s-opening-remarks-at-the-media-briefingon-covid-19---11-march-2020 .Lancet Infect Dis. $2020 \mathrm{Feb}$ 19.pii:S1473-3099(20)30120-1.

2. Dong E, Du H, Gardner L. An interactive web-based dashboard to track COVID-19 in real time. Lancet Infect Dis. 2020 Feb 19. pii: S1473-3099(20)30120-1. [Epub ahead print] [Cited in 2020 March 20]. Available from: https://www.arcgis.com/apps/opsdashboard/index. html\#/bda7594740fd40299423467b48e9ecf6.

3. $\mathrm{Wu} \mathrm{Z}, \mathrm{McGoogan}$ JM. Characteristics of and Important Lessons from the Coronavirus Disease 2019 (COVID-19) Outbreak in China: Summary of a Report of 72314 Cases From the Chinese Center for Disease Control and Prevention. JAMA.2020 Feb 24. [Cited 2020 February 24]. Available from: https://jamanetwork.com/

4. Imperial College - COVID19-Global-Impact- 26-03-2020; Walker PGT, Whittaker C, Watson O, The Global Impact of COVID-19 and Strategies for Mitigation and Suppression. WHO Collaborating Centre for Infectious Disease Modelling, MRC Centre for Global Infectious Disease Analysis, Abdul Latif Jameel Institute for Disease and Emergency Analytics, Imperial College London (2020). [Cited in 2020 March 20]. Available from: https://www.imperial.ac.uk/media/ imperial-college/medicine/sph/ide/gida-fellowships/ImperialCollege-COVID19-Global-Impact-26-03-2020.pdf

5. Huang C, Wang Y, Li X, Ren L, Zhao J, Hu Y, et al. Clinical features of patients infected with 2019 novel coronavirus in Wuhan, China. Lancet. 2020; 395(10223):497-506.

6. Onder G, Rezza G, Brusaferro S. Case-Fatality Rate and Characteristics of Patients Dying in Relation to COVID-19 in Italy. JAMA. 2020 March 23. DOI: 10.1001/jama.2020.4683. [Epub ahead of print]

7. Li B, Yang J, Zhao F, Zhi L, Wang et al, Prevalence and impact of cardiovascular metabolic diseases on COVID-19 in China. Clin Res Cardiol. 2020 Mar 11. DOI: 10.1007/s00392-020-01626-9. [Epub ahead of print]

8. Driggin E, Madhavan MV, Bikdeli B, Chuich T, Laracy J, BondiZoccai G, et al. Cardiovascular Considerations for Patients, Health Care Workers, and Health Systems During the Coronavirus Disease 2019 (COVID-19) Pandemic, J am Coll Cardiol. 2020 Mar 18. Pii:S0735-1097(20)34637-4 [Epub ahead of print]

9. Wang D, Hu B, Hu C, Zhu F, Liu X, Zhang J, et al. Clinical characteristics of 138 hospitalized patients with 2019 novel coronavirus-infected pneumonia in Wuhan, China. JAMA. 2020 Feb 7. DOI:10.1001/ jama.2020.1585.[Epub ahead of print]

10. Lippi G, Lavie CJ, Sanchis-Gomar F. Cardiac troponin I in patients with coronavirus disease 2019 (COVID-19): Evidence from a metaanalysis. Prog Cardiovasc Dis. 2020 Mar 10. pii: S0033-0620(20)30055-4. [Epub ahead of print]

11. Zhou F, Yu T, Du R, Fan G, Liu Y, Xiang J, et al. Clinical course and risk factors for mortality of adult inpatients with COVID-19 in Wuhan, China: a retrospective cohort study. Lancet. 2020 Mar 28;395(10229):1054-62.

12. Ruan Q, Yang K, Wang W, Jiang L, Song J. Clinical predictors of mortality due to COVID-19 based on an analysis of data of 150 patients from Wuhan, China. Intensive Care Med. 2020 Mar 3. DOI: 10.1007/ s00134-020-05991-x [Epub ahead of print]

13. Xu Z, Shi L, Wang $Y$, Zhang J, Huang L, Zhang C, et al. Pathological findings of COVID-19 associated with acute respiratory distress syndrome. Lancet Respir Med. 2020 Feb 18. pii:S221-32600(20)30076-X [Epub ahead of print]

14. Liu Y, Yang Y, Zhang C, Huang F, Wang F, Yuan J, et al. Clinical and biochemical indexes from 2019-nCoV infected patients linked to viral loads and lung injury. Sci China Life Sci. 2020; 63(3):364-74.

15. Inciardi RM; Lupi L, Zaccone G, Italia L, Raffo M, Tomasoni $\mathrm{D}$, et al. Cardiac Involvement in a Patient With Coronavirus Disease 2019 (COVID-19) JAMA Cardiol.2020 Mar 27. DOI:10.1001/ jamacardio.2020.1096 [Epub ahead of print]

16. Oudit GY, Kassiri Z, Jiang C, Liu PP, Poutanen SM, Penninger JM, et al. SARS coronavirus modulation of myocardial ACE2 expression and inflammation in patients with SARS. Eur J Clin Invest. 2009; 39(7):618-25.

17. Vaduganathan M, Vardeny O, Michel T, McMurray JJV, Pfeffer MA, Salomon SD. Renin-Angiotensin-Aldosterone System Inhibitors in Patients with Covid-19DOI: March 30, 2020, N Engl J Med.2020 March 30. [Epub ahead of prnt]

18. Zheng YY, Ma YT, Zhang JY, Xie X. COVID-19 and the cardiovascular system. Nat Rev Cardiol. 2020 Mar 5. DOI: 10.1038/s41569-020-0360-5 [Epub ahead of print] 
19. Gurwitz D. Angiotensin receptor blockers as tentative SARS-CoV-2 therapeutics. Drug Dev Res. 2020 Mar 4. DOI: 10.1002/ddr.21656. [Epub ahead of print]
20. Clerkin KJ. Justin A. Fried, MD, Raikhelkar J., Sayer G, Griffin JM, et al. Coronavirus Disease 2019 (COVID-19) and Cardiovascular Disease. DOI: 10.1161/CIRCULATIONAHA.120.046941 [Epub ahead of print] 